\title{
ANALISIS PERHITUNGAN BUNGA TABUNGAN UNTUK MENGHITUNG PPH FINAL PASAL 4 AYAT 2 YANG HARUS DIPOTONG PADA NASABAH BANK SULUTGO CABANG BITUNG
}

\author{
Felicia Maria Kalangi ${ }^{1}$, Inggriani Elim ${ }^{2}$, Lidia M. Mawikere ${ }^{3}$ \\ ${ }^{1,2,3}$ Fakultas Ekonomi dan Bisnis, Jurusan Akuntansi, Universitas Sam Ratulangi, Jl.Kampus Bahu, Manado, \\ 95115, Indonesia \\ Email : Felicia.m.kalangi@gmail.com
}

\begin{abstract}
One of the objects of income tax article 4 paragraph 2 is the interest on savings. Every customer who saves in the bank will get interest on their savings and the interest will be taxed at a rate of $20 \%$ of the gross amount. The research objective was to find out the savings interest calculation and calculate the final income tax article 4 paragraph 2 that must be deducted at the Bank SulutGo customer in the Bitung branch and whether the final PPh deduction in Article 4 paragraph 2 was in accordance with the applicable tax regulations. The analytical method used is descriptive method, in the form of interviews and documentation. The results of the study show that Bank SulutGo Branch Bitung uses the daily balance method to calculate savings interest. Savings interest will be calculated automatically by the system and channeled directly to the customer's account. The tax rate imposed by Bank SulutGo in the Bitung Branch is in accordance with Law No. 36 of 2008 and PP No. 123 of 2015 which is $20 \%$ of the gross amount of interest.
\end{abstract}

Keywords: Savings Interest Calculation, Final Income Tax Article 4 paragraph 2

\section{PENDAHULUAN}

Sumber pendanaan bank salah satunya didapat dari tabungan. Disaat seseorang menggunakan produk bank berupa tabungan, maka nasabah akan mendapatkan bunga berdasarkan suku bunga tabungan yang ditetapkan oleh bank. Bunga tabungan ini diberikan oleh bank agar dapat memberikan rangsangan kepada nasabah yang menempatkan dananya, dan akan selalu meningkatkan simpanan dananya. Membahas tentang suku bunga tabungan maka tidak akan terlapas dari PPh Final pasal 4 ayat 2 atas bunga deposito serta tabungan. Pemotongan PPh Final Pasal 4 ayat (2) terhadap bunga tabungan dilakukan setiap kali terhitungnya pemberian bunga kepada nasabah atas deposito baik jangka panjang ataupun jangka pendek dan tabungan. Perhitungan pajak atas bunga simpanan tabungan akan mempengaruhi jumlah bunga yang akan diterima nasabah. Berdasarkan peraturan pemerintah yang diatur dalam undang-undang pajak penghasilan pasal 4 ayat 2 bahwa terdapat tarif pph atas bunga simpanan tabungan adalah 20\% (dua puluh persen) dari jumlah bruto bunga dan bersifat final. Perhitungan Pajak atas Bunga akan mempengaruhi jumlah bunga yang akan diterima nasabah.

PT. Bank SulutGo Cabang Bitung adalah perusahaan bergelut dalam bidang perbankaan yang mempunyai produk antara lain simpanan dalam bentuk tabungan, giro, dan deposito. Terdapat 6 (enam) jenis tabungan yang ditawarkan kepada nasabah yaitu simpeda, tabunganku, tabungan simpel, tabungan PNS, tabungan bunaken, dan tabungan bohusami. Maksud observasi ini ialah agar mengetahui bagaimana cara menghitung bunga tabungan dan menghitung PPh final pasal 4 ayat 2 yang harus dipotong pada nasabah Bank SulutGo cabang Bitung, dan untuk mengetahui apakah pemotongan $\mathrm{PPh}$ final pasal 4 ayat 2 telah sesuai dengan peraturan perpajakan yang berlaku. 


\section{TINJAUAN PUSTAKA}

Akuntansi. Akuntansi merupakan proses mengidentifikasi, mengukur dan melaporkan informasi ekonomi untuk membuat pertimbangan dan mengambil keputusan yang tepat bagi pemakai informasi tersebut (Banguna, Pangemanan, Runtu, 2018:328).

Akuntansi Perpajakan. Akuntansi perpajakan ialah akuntansi yang melalui faktor khusus yang berdasarkan pada keahlian terhadap bidang tertentu. Akuntansi pajak berprinsip pada UU perpajakn yang terbentuk atas pengaruh fungsi perpajakan dalam melaksanakan kebijakan fiskus (Dunggio, Elim, Mawikere, 2018:141). Akuntansi perpajakan adalah bagian akuntansi yang terkait oleh perhitungan pajak, peraturan, undang-undang serta aturan pelaksanaan perpajakan (Rumbaru, Elim, Kalalo, 2018:39).

Pajak. Menurut Mardiasmo (2018: 3) Pajak ialah pungutan rakyat dan disetor ke kas Negara yang dapat dipaksakan dan tidak mengharapkan kontraprestasi dan yang bisa dipakai dalam membayar pengeluaran umum.

Fungsi Pajak. Menurut Resmi (2014:3) fungsi pajak yaitu sebagai sumber dana salah satu sumber penerimaan pemerintah untuk membiayai pengeluaran baik rutin maupun pembangunan, dan sebagai alat untuk mengatur atau melaksanakan kebijakan dibidang sosial dan ekonomi.

Tarif Pajak. Menurut Mardiasmo (2018: 11) tarif pajak dibedakan menjadi :

1. Tarif proposional/sebanding. Tarif proposional ialah tarif yang presentasenya tetap, meskipun terjadi perubahan terhadap dasar pengenaan paajak.

2. Tarif tetap. Tarif tetap ialah tariff yang nominalnya tetap tanpa memperhatikan jumlah dasar pengenaan pajak.

3. Tarif progresif. Tarif pungutan yang dipakai lebih besar jika total yang dikenai pajak semakin besar.

4. Tarif degresif. Tarif pungutan yang dipakai lebih kecil jika total yang dikenakan pajak semakin besar.

\section{Dasar Hukum}

1. UU nomor 36 tahun 2008. Pasal 4 ayat (2) undang-undang nomor 7 tahun 1983 mengenai pajak penghasilan berdasarkan yang telah diubah terakhir dengan undang-undang nomor 36 tahun 2008. Dimana subjek pajak penghasilan ialah orang pribadi, badan, dan bentuk usaha tetap.

2. PP No. 131 tahun 2000 sebagaimana telah diubah terakhir dengan peraturan pemerintah No. 123 Tahun 2015. Aturan ini berlaku sejak 28 desember 2015 menggantikan PP nomor 131 tahun 2000 tentang $\mathrm{PPh}$ atas bunga deposito, tabungan, dan diskonto SBI yang diperoleh wajib pajak dalam negeri serta BUT dikenakan pajak penghasiln bersifat final.

3. $K M K-51 / K M K .04 / 2001$. Aturan ini yang berlaku 1 januari 2001 menggantikan KMK No. 652/KMK.04/1994 mengenai pemotongan PPh atas bunga deposito, tabungan, dan diskonto SBI. Aturan yang berisi mengenai wajib pajak, pihak pemotong, tariff pajak, objek pajak, pengecualian pemotongan pajak sesuai yang diatur dalam PP No. 131 tahun 2000.

Pemotongan Pajak Penghasilan Pasal 4 ayat 2. Menurut Waluyo (2013:341) Yang wajib melakukan pemotongan adalah :

1. Bank dan Bank Indonesia sebagai pemberi bunga Deposiito, bunga Tabungn dan diskkonto SBI.

2. Bank serta daana pnsiun, dan yang menjual kembli SBI sertifiikat deposito pada pihak lain ialah bukan bank serta uang pensiun yang nantiya akan disahkan menteri keuangan.

3. Kantor pusat bank yang berdiri di Indonesia terhadap bunga deposito serta bunga tabungan yang berkeududkan dilluar negeri lewat cabang bank yang ada di Indonesia tersebut. 
4. Cabang bank luar negeri yang ada di Indonesia terhadap bunga deposito serta bunga tabngan berkedudukan diluar negeri lewat cabang bank luar negeri di Indonesia.

Tarif PPh Final Pasal 4 Ayat 2 Berdasarkan PP No. 123 Tahun 2015

a. Terhadap bunga deposito dengan mata uang dolar Amerika Serikat oleh bank yang ada di Indonesia maupun cabang bank luar negeri yang ada di Indonesia dikenai maka tariff PPh final ialah : Deposito berjangka waktu sebulan dikenai tarif $10 \%$ dari nilai bruto, Deposito berjangka waktu 3 bulan dikenai tarif 7,5\% dari nilai bruto, Deposito berjangka waktu 6 bulan dikenai tarif 2,5\% dari nilai bruto, dan Deposito berjangka waktu melebihi 6 bulan dikenai tarif $0 \%$ dari nilai bruto.

b. Terhadap bunga deposito dengan mata uang rupiah oleh bank yang ada di Indonesia maupun cabang bnk luar negeri yang ada di Indonesia maka dikenakan tariff PPh final : Deposito berjangka waktu sebulan dikenai tarif 7,5\% dari nilai bruto, Deposito berjangka waktu 3 bulan dikenai tarif 5\% dari nilai bruto, dan Deposito berjangka waktu 6 bulan atau melebihi 6 bulan tarif $0 \%$ dari total bruto.

c. Terhadap bunga tabungan bahkan diskon SBI, dan bunga deposito selain yang diatas dikenakan tarif : Wajib Pajak (WP) dalam negeri dan BUT tarif $20 \%$ dari nilai bruto, dan Wajib Pajak luar negeri tarif $20 \%$ dari nilai bruto.

Pengecualian Pemotongan PPh Pasal 4 Ayat 2. Menurut Mardiasmo (2018: 310)

$\mathrm{PPh}$ final pasal 4 ayat 2 dikecualikan jika :

1. Jumlah bunga deposito, tabungan, dan diskonto SBI bukan lebih dari Rp 7.500.000,00 dan bukan nilai yang terpecah.

2. Bunga dan diskonto yang diterima yang berdiri di Indonesia atau cabang bank luar negeri yang ada di Indonesia.

3. Bunga deposito, tabungan dan diskon SBI yang diterima dari Dana Pensiun yang diberikan berdasarkan Surat Keterangan Bebas (SKB) Pemotongan Pajak Penghasilan atas bunga deposito dan tabungan dan diskonto SBI.

4. Bunga tabungan pada bank yang diajukan Pemerintah terkait kepemilikan rumah sederhana dan rumah susun sederhana.

5. Bunga dan diskon tidak melebihi Penghasilan Tidak Kena Pajak dalam 1 tahun pajak.

Pengertian Bank. Menurut Kasmir (2013: 24) bank ialah lembaga keuangan yang aktivitas utamanya ialah menerima simpanan tabungan, deposito, giro, juga sebagai tempat menukar uang dan segala bentuk pembayaran. Bank juga menyediakan jasa pinjaman uang untuk masyarakat yang memerlukan.

Sumber Dana Bank. Sumber dana bank tergantung pada bank itu sendiri, bisa dari simpanan nasabah atau dari lembaga lain (Kasmir, 2013: 68). Sumber pendanaan bank diperoleh dari :

1. Dana bank sendiri. Berupa setoran modal yang didapat dari pemegang saham, persediaan keuntungan, dan keuntungan bank yang belum dibagi.

2. Dana Masyarakat Luas atau dana pihak ketiga yaitu berupa tabungan, deposito, dan giro.

3. Dana dari Lembaga Lainnya. Perolehan dana dari sumber ini yaitu : Pinjaman antar bank (Call Money), Surat Berharga Pasar Uang (SBPU), dan Bantuan Likuiditas Bank Indonesia (BLBI), dan Pinjaman dari bank-bank luar negeri.

4. Dana Pihak Ketiga. Dana Pihak Ketiga (DPK) adalah dana dalam rupiah maupun valas milik pihak ketiga bukan bank, yang terdiri dari tabungan,simpanan berjangka, dan giro.

Perhitungan Suku Bunga Tabungan. Dalam menetapkan total hari dalam satu tahun, bank menggunakan 365 hari, namun ada pula yang menggunakan 360 hari. Menurut Sunariyah (2013: 92) Perhitungan bunga tabungan ada tiga metode yaitu :

Metode saldo terendah. Bunga tabungan akan dihitung sesuai dengan saldo terendah dalam bulan laporan dan saldo tersebut digunakan untuk menghitung bunga.

Bunga $=$ Saldo terendah $\times$ suku bunga tabungan per tahun $\times$ jumlah hari dalam bulan berjalan/jumlah hari dalam 1 tahun (365) 
Metode saldo rata-rata. Perhitungan bunga berdasarkan saldo rata-rata yang menjadi acaun dalam menghitung bunga.

Bunga $=$ Saldo rata-rata harian $x$ suku bunga tabungan per tahun $x$ jumlah hari dalam bulan berjalan/jumlah hari dalam 1 tahun (365)

Metode saldo harian. Perhitungan bunga didasarkan atas besarnya saldo harian pada bulan berjalan.

\section{Bunga $=$ Saldo Harian $x$ suku bunga tabungan per tahun $x$ jumlah hari dalam bulan berjalan/jumlah hari dalam 1 tahun (365)}

Penelitian Terdahulu. Yulia (2017) Analisis Perhitungan Tingkat Suku Bunga Simpanan Tabungan Guna Menghitung Pph Final Pasal 4 Ayat 2 Yang Harus Dipotong Pada Nasabah PD. BPR Bank Daerah Kabupaten Kediri. Tujuan penelitian yaitu untuk mengetahui bagaimana Perhitungan Tingkat Suku Bunga Simpanan Tabungan Guna Menghitung Pph Final Pasal 4 Ayat 2 Yang Harus Dipotong Pada Nasabah PD. BPR Bank Daerah Kabupaten Kediri. Peneliti menggunakan metode kuantitatif. Hasil penelitian ialah perhitungan tingkat suku bunga simpanan tabungan takwa menjadi salah satu faktor yang mempengaruhi $\mathrm{PPh}$ Final Pasal 4 Ayat 2 yang harus dipotong pada nasabah PD. Bank Perkreditan Rakyat Daerah Kabupaten Kediri. Tangka (2014) Analisis Perhitungan PPh Final Pasal 4 Ayat 2 Atas Bunga Deposito dan Tabungan Nasabah Pada PT. Bank Rakyat Indonesia (Persero) Tbk, Cabang Manado. Bertujuan untuk agar dapat mengetahui PPh Final Pasal 4 Ayat 2 Atas Bunga Deposito dan Tabungan Nasabah Pada PT. Bank Rakyat Indonesia (Persero) Tbk, Cabang Manado apakah telah sesuai dengan UU yang berlaku. Menggunakan metode kualitatif. Hasil studi menunjukan Perhitungan bunga dan pemotongan PPh Final atas bunga deposito, tabungan nasabah pada PT. Bank Rakyat Indonesia (Persero) Tbk, Cabang Manado sudah sesuai dengan undang-undang yang berlaku.

\section{METODE PENELITIAN}

Jenis Penelitian. Penelitian ini menggunakan jenis penelitian deskriptif kualitatif. Peneliti mendeskripsikan dan menganalisis situasi serta permasalahan yang ada, khususnya mengenai perhitungan tingkat suku bunga tabungan untuk menghitung $\mathrm{PPh}$ final pasal 4 ayat 2 yang harus dipotong pada nasabah bank SulutGo Cabang Bitung.

Tempat dan Waktu Penelitian. Tempat yang dipilih sebagai lokasi penelitian sesuai dengan judul penelitian dilakukan yaitu pada PT Bank SulutGo Cabang Bitung dengan alamat Jalan Yos Sudarso 13/12, Kecamatan Maesa, Bitung. Waktu penelitian dimulai dari bulan Mei tahun 2018 sampai dengan selesainya penelitian.

\section{Jenis, Sumber, dan Metode Pengumpulan Data}

Jenis Data. Penelitian ini menggunakan jenis data kualitatif dan kuantitatif.

1. Data kualitatif dalam penelitian ini berisi hasil wawancara tentang penerapan PPh final pasal 4 ayat 2 dan data dalam bentuk uraian perusahaan ialah: sejarah, visi dan misi, serta struktur organisasi dari PT Bank SulutGo Cabang Bitung.

2. Data Kuantitatif dalam penelitian ini berupa data mutasi rekening nasabah yang menempatkan uangnya pada Bank SulutGo. Mutasi rekening yang dijadikan penelitian adalah rekening tabungan.

Sumber Data. Sumber data yang digunakan ialah data primer. Data primer diperoleh dari hasil wawancara secara langsung pada karyawan analisis akuntansi dan laporan PT. Bank SulutGo cabang Bitung mengenai mekanisme perhitungan pajak bunga tabungan dan data mutasi rekening, serta bagaimana perlakuan akuntansi yang diterapkan.

Metode Penelitian. Metode pengumpulan data dalam penelitian ini dilakukan dengan cara sebagai berikut: 
1. Metode wawancara secara langsung, suatu metode yang bertujuan untuk mendapatkan dan mengumpulkan data dengan mengadakan wawancara dalam hal ini dengan karyawan Bank SulutGo Cabang Bitung mengenai mekanisme perhitungan bunga dan pemotongan pajak bunga.

2. Dokumentasi merupakan teknik pengumpulan data dengan cara memeriksa atau melihat secara langsung dokumen dan catatan-catatan mengenai perhitungan bunga tabungan dan perhitungan $\mathrm{PPh}$ final pasal 4 ayat 2.

Metode dan Analisis Penelitian. Metode analisis data dalam penelitian ini adalah analisis deskriptif, yaitu mengumpulkan, menghitung, serta mengevaluasi perhitungan pajak bunga dana pihak ketiga. Alat analisis yang digunakan dalam penelitian ini menggunakan perhitungan bunga dengan tiga metode yaitu metode saldo terendah, saldo rata-rata, dan saldo harian. Peneliti akan menghitung perhitungan PPh pasal 4 ayat 2 yang harus dipotong pada nasabah yaitu 20\% dikalikan dengan Jumlah Bunga. Selanjutnya, setelah mengolah data peneliti akan menganalisis perbandingan perhitungan PPh final pasal 4 ayat 2 atas bunga tabungan nasabah menurut PT. Bank SulutGo cabang bitung dengan perhitungan PPh final pasal 4 ayat 2 atas bunga tabungan nasabah berdasarkan peraturan perpajakan yang berlaku.

\section{HASIL PENELITIAN DAN PEMBAHASAN}

4.1. Hasil Penelitian

Berikut adalah suku bunga tabungan jenis PNS dan Simpeda :

Tabel 1. Suku Bunga Tabungan Simpeda dan Tabungan PNS Bank SulutGo

\begin{tabular}{lc}
\hline \multicolumn{1}{c}{ Nominal } & Bunga (\%/pa) \\
\hline s/d Rp.10.000.000,- & 1.00 \\
Rp. 10.000.001,- s.d Rp. 100.000.000,- & 1.25 \\
Rp.100.000.001,- s.d Rp. 500.000.000,- & 1.75 \\
Rp. 500.000.001 s.d Rp. 1.000.000.000,- & 2.25 \\
> Rp. 1.000.000.000,- & 2.75 \\
\hline
\end{tabular}

Sumber : Bank SulutGo

\subsection{Pembahasan}

\section{Perhitungan Bunga Tabungan Nasabah Bank SulutGo Cabang Bitung}

1. Metode Saldo Terendah. Bunga per bulan didapat pada perhitungan saldo terendah bulan tersebut dikalikan suku bunga yang berlaku berdasarkan nominal saldo terendah tersebut, dikalikan dengan jumlah hari dalam bulan yang dilaporkan atau sementara dihitung kemudian dibagi dengan total hari dalam 1 tahun (365). Tabel 4.6 menunjukan bahwa transaksi nomor rekening (005021100xxxx) memiliki saldo terendah Rp.64.559.207 pada tanggal 14 Mei 2018. Berikut hasil perhitungan bunganya :

$$
\begin{aligned}
\text { Bunga } & =\text { ST x I x T / 365 } \\
& =\operatorname{Rp} .64 .559 .207 \times 1.25 \% \text { x } 31 / 365 \\
& =\text { Rp. } 68.538,89
\end{aligned}
$$

2. Metode Saldo Rata Rata, untuk mendapatkan jumlah saldo rata - rata maka bunga per bulan dapat dihitung dengan mengalikan jumlah saldo tersebut dengan suku bunga yang berlaku berdasarkan tingkatan jumlah saldo sebelumnya lalu dikali total hari dalam bulan berjalan kemudian dibagi total hari dalam satu tahun (365). Berdasarkan tabel diatas diketahui saldo rata-rata nasabah dengan nomor rekening (0050211000xxxxx) adalah Rp.129.409.760,35. Berikut perhitungan bunganya:

Bunga $=$ SRH $\times$ I $\times$ T $/ 365$

$$
=\mathrm{Rp} .129 .409 .760,35 \times 1.75 \% \text { x } 30 / 365
$$




$$
=\text { Rp. 186,137.33 }
$$

3. Metode Saldo Harian, bunga per bulan didapat dari total bunga harian. Perhitungan bunga harian dilakukan dengan suku bunga yang berlaku berdasarkan nominal saldo sesuai ketentuan yang ada, dikalikan dengan jangka waktu bulan yang dilaporkan atau sementara dihitung. Kemudian dibagi dengan total hari dalam 1 tahun (365). Berdasarkan tabel diatas maka bunga yang akan di terima pada akhir bulan oleh nasabah dengan nomor rekening (0050211000xxxxx) adalah Rp. 179,281.94.

Perhitungan Pajak Penghasilan Pasal 4 ayat 2 yang harus dipotong. Berikut perhitungan pemotongan pajak penghasilan pasal 4 ayat 2 pada nasabah :

1. Jika suku bunga tabungan dihitung dengan metode saldo terendah, maka tabungan nasabah harus dipotong pajak sebesar :

$\mathrm{PPh}$ pasal 4 ayat $2=$ Pendapatan bunga bruto $\mathrm{X} 20 \%$

$=$ Rp. $68.538,89 \times 20 \%$

$=$ Rp. 13.707,78

Setelah dipotong pajak maka nasabah akan mendapatkan bunga bersih yaitu :

Bunga Setelah dipotong Pajak = Rp. 68.538,89-Rp. 13.707,78

$$
=\operatorname{Rp} .54 .831 .11
$$

2. Jika suku bunga tabungan dihitung dengan metode saldo rata-rata, maka tabungan nasabah harus dipotong pajak sebesar :

$$
\begin{aligned}
\text { PPh pasal } 4 \text { ayat } 2 & =\text { Pendapatan bunga bruto X 20\% } \\
& =\text { Rp. } 186.137,33 \times 20 \% \\
& =\text { Rp. } 37.227,466
\end{aligned}
$$

Setelah dipotong pajak maka nasabah akan mendapatkan bunga bersih yaitu :

Bunga Setelah dipotong pajak $=$ Rp. 186.137,33 - Rp. 37.227,466

$$
=\text { Rp. 148.909,864 }
$$

3. Jika suku bunga tabungan dihitung dengan metode saldo terendah rata-rata, maka tabungan nasabah harus dipotong pajak sebesar:

$\mathrm{PPh}$ pasal 4 ayat 2

$$
\begin{aligned}
& =\text { Pendapatan bunga bruto X 20\% } \\
& =\text { Rp.179.281,94 X 20\% } \\
& =\text { Rp. } 35.856
\end{aligned}
$$

Setelah dipotong pajak maka nasabah akan mendapatkan bunga bersih yaitu :

Bunga setelah dipotong pajak $=$ Rp.179.281,94 - Rp. 35.800

$$
=\text { Rp. } 143.481,94
$$

\section{KESIMPULAN DAN SARAN}

\subsection{Kesimpulan}

1. Berdasarkan hasil penelitian diketahui bahwa PT Bank SulutGo Cabang Bitung menggunakan metode saldo harian untuk menghitung bunga tabungan. Bunga tabungan dihitung oleh sistem secara otomatis kemudian disalurkan pada rekening nasabah setiap bulannya.

2. PT. Bank SulutGo Cabang Bitung menetapkan tarif sesuai dengan UU No. 36 Tahun 2008 dan PP No. 123 Tahun 2015 yaitu 20\% dari total bruto. Tarif ini dikenakan pada saat total tabungan nasabah lebh dari Rp. 7.500.000 dan bukan nilai yang terbagi-bagi.

\subsection{Saran}

1. Lebih ditingkatkan lagi pelayanannya agar memuaskan nasabah baik dalam pemberian simpanan maupun pinjaman sehingga dapat menjadi bank yang unggul dan dipercaya oleh masyarakat.

2. Kiranya PT. Bank SulutGo Cabang Bitung bisa terus mempertahankan kepatuhan perpajakan yang telah dilaksanakan selama ini agar terhindar dari sanksi yang bisa saja terjadi. 
3. Kiranya bisa memberikan pelayanan yang baik untuk peneliti-peneliti selanjutnya yang akan melakukan penelitian di PT. Bank SulutGo Cabang Bitung.

\section{DAFTAR PUSTAKA}

Baguna, Pangemanan, Runtu. 2018. Analisis perhitungan dan pelaporan pajak penghasilan pasal 21 pegawai tetap pada PT. Bank Rakyat Indonesia. Jurnal riset akuntansi going concern 12(2):327-335.

Dunggio, Elim, Mawikere. 2018. Analisis penerapan peraturan pemerintah nomor 46 tahun 2013 terhadap pertumbuhan jumlah wajib pajak dan penerimaan PPh pasal 4 ayat 2 Jurnal riset going concern 12(2):140-148.

Kasmir. 2014. Bank dan lembaga keuangan lainnya. Edisi revisi. PT Gramedia widiasarana. Jakarta

Mardismo. 2018. Perpajakan. Edisi Revisi. Yogyakarta : Andi offset

Peraturan Menteri Keuangan (PMK) Nomor: 26/ PMK. 010/ 2016. Perubahan Atas Keputusan Menteri Keuangan Nomor 51/ KMK.04/2001 tentang Pemotongan Pajak Penghasilan (PPh) atas Bunga Deposito, Tabungan, serta Diskonto Sertifikat Bank Indonesia

Peraturan Pemerintah Nomor 123 Tahun 2015. Perubahan atas peraturan pemerintah nomor 131 tahun 2000 tentang pajak penghasilan bunga deposito dan tabungan serta diskonto sertifikat bank Indonesia. 28 Desember 2015. Jakarta

Resmi. 2014. Perpajakan: teori dan kasus. Edisi 5 buku 1. Jakarta: Salemba Empat

Rumbaru, Elim, Kalalo. 2018. Penerapan akuntansi penyusutan asset tetap berdasarkan pernyataan standarakuntansi pemerintah nomor 07 pada dinas pekerjaan umum provinsi Sulawesi utara. Jurnal riset going concern 13(2):38-45.

Sunariyah. 2013. Pegantar pengetahuan pasar modal. UPP-STIM YKPN. Yogyakarta

Tangka. 2014. Analisis Perhitungan PPh Final Pasal 4 Ayat 2 Atas Bunga Deposito dan Tabungan Nasabah Pada PT. Bank Rakyat Indonesia (Persero) Tbk, Cabang Manado. Skripsi Universitas Sam Ratulangi

Undang-Undang Republik Indonesia Nomor 36 Tahun 2008. Perubahan keempat atas UU No.7 tahun 1983 tentang pajak penghasilan. 23 September 2008. Jakarta

Waluyo. 2013. Perpajakan Indonesia. Edisi 11. Salemba empat. Jakarta

Yulia. 2017. Analisis Perhitungan Tingkat Suku Bunga Simpanan Tabungan Guna Menghitung Pph Final Pasal 4 Ayat 2 Yang Harus Dipotong Pada Nasabah PD. BPR Bank Daerah Kabupaten Kediri. Skripsi. Universitas Islam. Kediri 